\title{
Finnish Current Care Guideline for Diabetes: interactive approach to improve individualised treatment
}

\author{
A. Virkamäki • J. Saltevo
}

Received: 8 November 2010 /Accepted: 13 December 2010/Published online: 18 February 2011

(C) Springer-Verlag 2011

Keywords Algorithms · Clinical guidelines $\cdot$ Diabetes guidelines $\cdot$ Guidelines

\section{Abbreviation \\ FCCD Finnish Current Care Guideline for Diabetes}

To the Editor: Dr R. Kahn recently wrote a Commentary in Diabetologia regarding the need to improve clinical guidelines [1]. We would like to highlight some practical and readily available ways of overcoming many of the problems raised by Kahn in his excellent paper.

The Finnish Current Care Guideline for diabetes (FCCD) [2] was published in 2007 and is authorised by the Finnish Medical Society Duodecim and the Finnish Society of Internal Medicine. The guideline treats the timing of the clinical decision for intervention as the main priority. Several approaches have been used.

A. Virkamäki is the coordinating writer of the FCCD;

J. Saltevo is a member of the FCCD.

A. Virkamäki $(\bowtie)$

Mehiläinen Diabetes Clinic,

Pohj. Hesperiankatu $17 \mathrm{C}$,

FI-00260 Helsinki, Finland

e-mail: antti.virkamaki@mehilainen.fi

J. Saltevo

Department of Medicine, Central Finland Central Hospital,

Jyväskylä, Finland
Publication Only a browser-operated online version of the FCCD is available, which offers several benefits. Online publication facilitates both the actual update process and enables a quick response to changes (e.g. withdrawal of a drug from the market). Most importantly, however, online publication ensures that all healthcare professionals have the latest version of the guideline at their disposal. In addition, it means that the guideline is readily available at the physician's office.

As an electronic document, the table of contents in the FCCD is linked to the corresponding section of the guideline so that readers can quickly locate the subject of interest. Each statement in the text is hyperlinked to a summary of supporting evidence and is graded by the level of evidence. The actual guideline is published in Finnish, but a summary is available in English [3].

Interactivity and personalisation Kahn raised important questions regarding personalised treatment and target setting as, in general, guidelines deal poorly with these issues. Guidelines on these were provided in the second update of the FCCD in 2009, after results from the Action to Control Cardiovascular Risk in Diabetes (ACCORD, [4]) study, the Veterans Affairs Diabetes Trial (VADT, [5]) and Action in Diabetes and Vascular Disease: Preterax and Diamicron Modified-Release Controlled Evaluation (ADVANCE, [6]) study were published. These studies emphasised the need for individual goal setting and treatment. The problem with most evidence-based guidelines is that they only deal with the average patient, without recognizing specific clinical features of the patient. In real life, however, many patients do not fit these criteria, and guidelines for these all too many outliers are lacking. The 
Fig. 1 Illustration of the strengths-weaknesses analysis of the FCCD using metformin as an example. Published with permission from the Finnish Medical Society Duodecim [2]

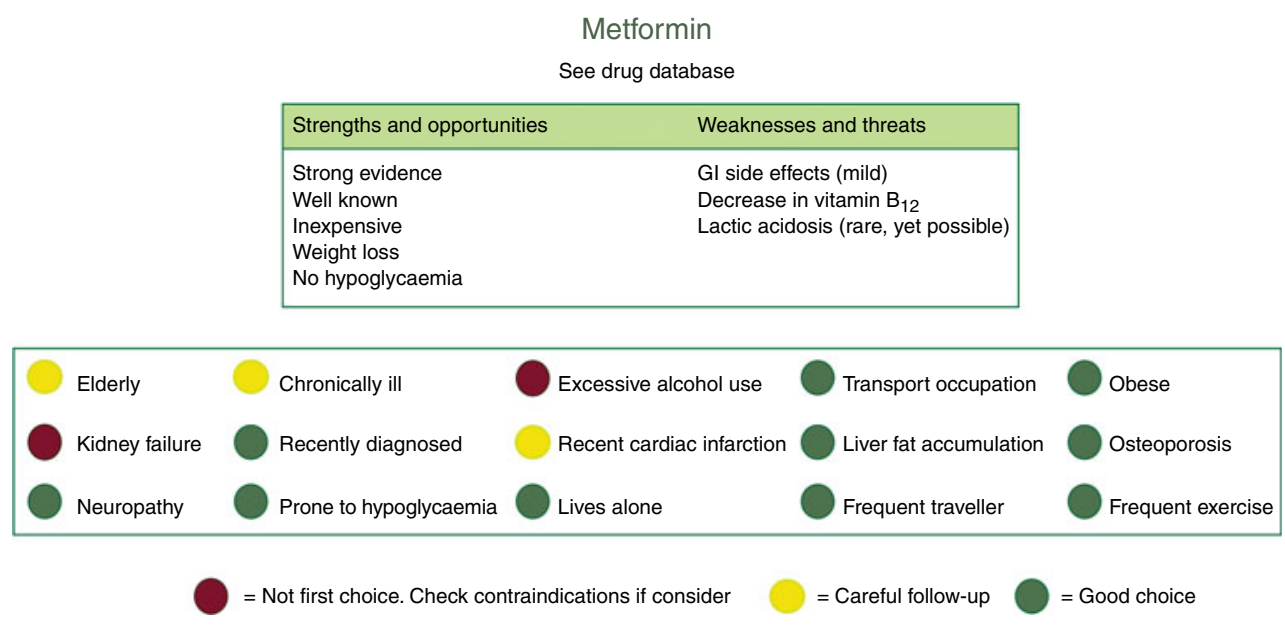

(C) The Finnish Medical Society Duodecim
FCCD contains an interactive algorithm (an English version of which is available [7]) that allows you to select the main feature of the clinical condition of the patient.

The FCCD includes six common clinical features, out of which the clinician is able to easily choose the one that most closely describes his patient. The selected situations/ features are 'early diabetes', 'chronic diabetes ( $>10$ years)', 'morbid obesity (BMI $>30 \mathrm{~kg} / \mathrm{m}^{2}$ )', 'elderly patient', 'transport occupation' and 'impaired kidney function'. The algorithm changes according to the chosen clinical feature to optimise the medical intervention and the goal. Within the algorithm the FCCD has a balanced strengthsweaknesses analysis for each drug class and even more detailed stratification of the clinical suitability of the selected therapy (Fig. 1).

Acknowledgements We thank the Finnish Medical Society Duodecim for technical support in the preparation of this letter.

Duality of interest The authors declare that there is no duality of interest associated with this manuscript.

\section{References}

1. Kahn R (2010) Guidelines: we'll always need them, we sometimes dislike them, and we have to make them better. Diabetologia 53:2280-2284

2. Diabetes Current Care Guideline. Working group set up by the Finnish Medical Society Duodecim and the Finnish Society of Internal Medicine. Helsinki: Finnish Medical Society Duodecim, 2009. Available from: www.kaypahoito.fi. Accessed 3 Nov 2010 (in Finnish)

3. Diabetes Current Care summary. Working group set up by the Finnish Medical Society Duodecim and the Finnish Society of Internal Medicine. Available from: www.kaypahoito.fi/web/kh/ suositukset/naytaartikkeli/tunnus/ccs00032

4. The Action to Control Cardiovascular Risk in Diabetes Study Group (2008) Effects of intensive glucose lowering in type 2 diabetes. N Engl J Med 358:2545-2559

5. Duckworth W, Abraira C, Moritz T et al (2009) Glucose control and vascular complications in veterans with type 2 diabetes. $\mathrm{N}$ Engl J Med 360:129-139

6. The ADVANCE Collaborative Group (2008) Intensive blood glucose control and vascular outcomes in patients with type 2 diabetes. N Engl J Med 358:2560-2572

7. Diabetes treatment algorithm from the Diabetes Current Care Guideline. Working group set up by the Finnish Medical Society Duodecim and the Finnish Society of Internal Medicine. Available from: www.terveysportti.fi/xmedia/ccs/varhainen_diabetes_en.html 